\title{
A Study on Psoriasis of Nails- Severity Scoring System
}

\author{
Sharada RG, Jayakar Thomas \\ ${ }^{1}$ Resident, ${ }^{2}$ Professor and Head, \\ ${ }^{1,2}$ Department of Dermatology, Sree Balaji Medical College \& Hospital and Bharath University, \\ Chromepet, Chennai, INDIA
}

\begin{abstract}
:
Objective: To observe nail changes in all psoriasis patients attending our OPD and to compare the findings between Nijmegen nail psoriasis Activity Index Tool (N-NAIL) and Nail Psoriasis Severity Index (NAPSI) with the clinical severity by using PASI score.
\end{abstract}

Materials and methods: Thirty patients with nail psoriasis were included in the study. Full history taking and clinical examination were done in all patients. The nails changes were observed in all psoriasis patients and interpreted according to Nijmegen Nail Psoriasis Activity Index Tool (N-NAIL) and Nail Psoriasis Severity Index (NAPSI) and compared with PASI score.

Results: A total of 30 patients (21 males and 9 females) were included in the study. The nail changes observed in our study were onycholysis (53\%), pitting (40\%), subungual hyperkeratosis (33\%), beau's lines (20\%), crumbling $(6 \%)$ and leukonychia (3\%). (10\%) had psoriatic arthritis. There was no correlation between both the scoring system and the severity of the disease.

Conclusion: In our study, we found that there was no correlation between both the scoring systems with the severity of the disease. Nail psoriasis seems to be an overlooked feature of the disease and hence an adequate nail psoriasis scoring system is necessary to prevent nail psoriasis.

Keywords: Nail psoriasis, Nijmegan nail psoriasis activity score (N-NAIL), Nail Psoriasis Severity Index (NAPSI).

\section{INTRODUCTION}

Psoriasis is an immunologically mediated inflammatory dermatosis which is characterized by erythematous scaly plaques, extremely variable in clinical manifestations ranging from innocuous lesions to life threatening pustular \& erythrodermic psoriasis. It can affect any part of the body including the scalp, nail, palms and soles. Psoriasis can affect the nails with an incidence rate of $10 \%$ to $56 \%$. ${ }^{[1]}$ Nail psoriasis in the absence of cutaneous disease is present in $5 \%$ to $10 \%$ of psoriasis patients. ${ }^{[2][3]}$ There is no sex predilection. Patients above 40 years of age are affected twice as often as those under 20 years. ${ }^{[4][5]}$ The prevalence of nail psoriasis associated with psoriatic arthropathy ranges from $50-87 \% .{ }^{[6][7]}$ Clinical findings diagnostic for nail psoriasis are pitting, oil drop or salmon patch, onycholysis, subungual hyperkeratosis, nail plate discoloration, beau lines, red lunula and splinter hemorrhage, which depends on the anatomical site and extent of involvement.

The present study was conducted to compare the nail changes in all psoriasis patients which includes onycholysis, pitting, crumbling, subungual hyperkeratosis, beau lines, leukonychia, oil spots and interpret according to Nijmegen Nail Psoriasis Activity Index Tool (N-NAIL) and Nail Psoriasis Severity Index (NAPSI) with clinical evaluation using PASI score.

\section{Materials AND Methods}

The study was conducted in the Department of Dermatology, Sree Balaji Medical College from January 2016 to February 2016. Thirty patients with nail psoriasis were included in our study. All the types of psoriasis were included in our study. Full history taking and complete physical examination was done in all patients. The nails changes were observed in all psoriasis patients and interpreted according to Nijmegen Nail psoriasis Activity Index Tool (N-NAIL) and Nail Psoriasis Severity Index (NAPSI) and compared with the PASI score. 


\section{Statistical Analysis}

Demographic variables and clinical variables in categorical/dichotomous were given in frequencies with their percentages. Nijmegen, NAPSI \& PASI score was given in mean and standard deviation. Correlation between Nijmegen score, NAPSI score and PASI score was analyzed using Karl Pearson correlation coefficient method. Comparison of mean Nijmegen, NAPSI \& PASI SCORE was analyzed using one-way analysis of Variance. Comparison of mean NAPSI SCORE \& PASI score was analyzed using student independent t-test. Age wise comparison of Nijmegen, NAPSI \& PASI score was analyzed using one-way analysis of Variance. Sex wise comparison of Nijmegen, NAPSI \& PASI SCORE was analyzed using student independent t-test. Type of psoriasis comparison of Nijmegen, NAPSI \& PASI SCORE was analyzed using one-way analysis of Variance. $\mathrm{P}<0.05$ was considered statistically significant.

\section{ReSults}

A total of 30 patients (21males and 9 females) were included in the study. Most common age group was in the range of 21-30 years (26.6\%) followed by $41-50$ years $(20.0 \%)$. [Figure 1 ] Twenty patients $(66.6 \%)$ had chronic plaque type psoriasis, five patients (16.7\%) had scalp psoriasis, two patients (6.7\%) had palmoplantar psoriasis, two patients (6.7\%) had plantar psoriasis and 1 patient $(3.3 \%)$ had nail psoriasis alone. [Figure 2] 3 patients (10\%) had psoriatic arthritis. There was positive correlation between the type of psoriasis with the scoring system (Nijmegan, NAPSI and PASI score). [Table 2] The nail changes observed in our study was onycholysis (53.3\%), pitting (40\%), subungual hyperkeratosis $(33.3 \%)$, beau's lines $(20 \%)$, crumbling (6.7\%) and leukonychia (3.3\%). [Figure 3] There was positive correlation between N-NAIL score and NAPSI score. [Table 1] There was no correlation between NAPSI score, N-NAIL score with the PASI score.

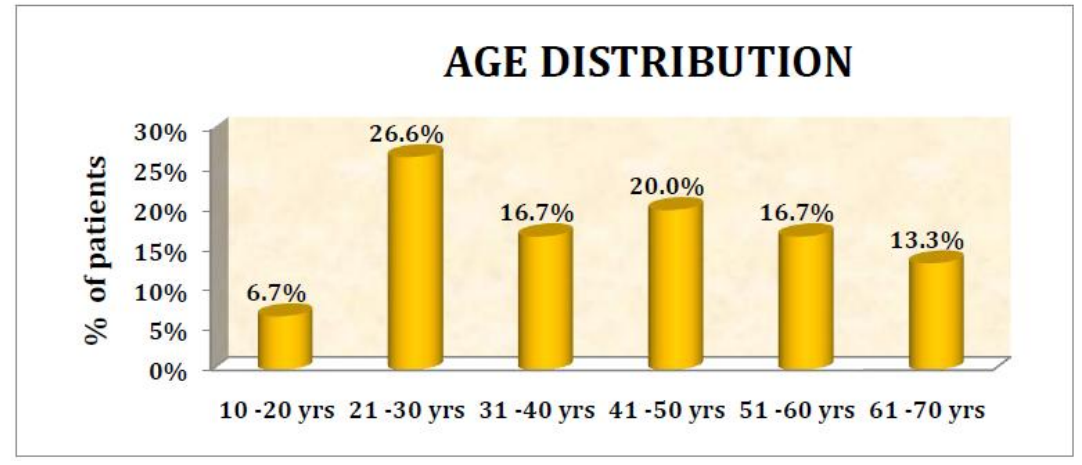

Figure1.

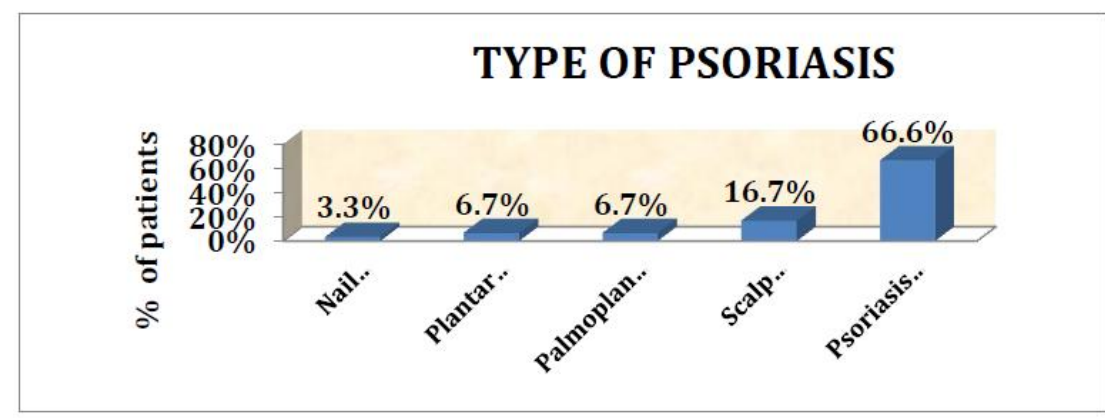

Figure2.

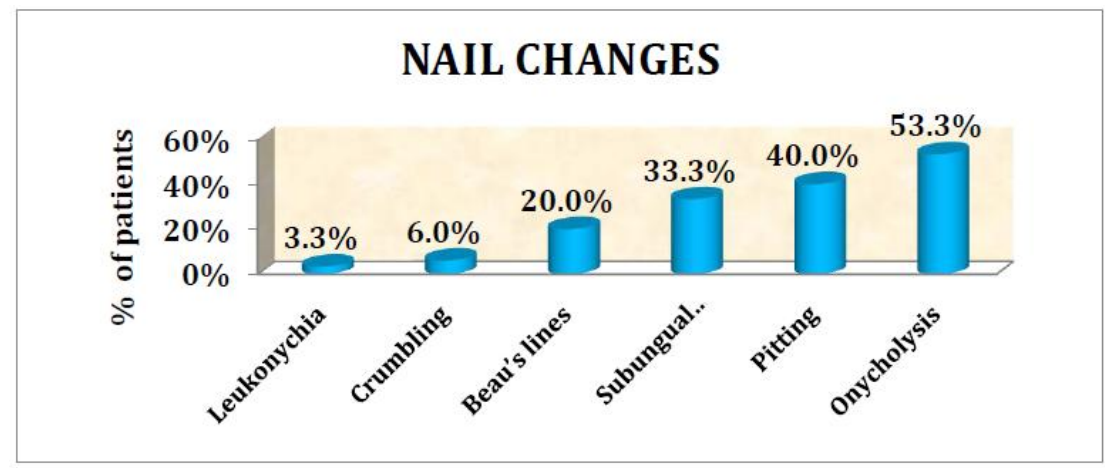

Figure3. 
A Study on Psoriasis of Nails- Severity Scoring System

Table1. Correlation Between Nijmegen Score Napsi Score Pasi Score

\begin{tabular}{|l|l|l|l|}
\hline & Mean \pm SD & $\begin{array}{l}\text { Karl Pearson } \\
\text { Correlation } \\
\text { Coefficient }\end{array}$ & Interpretation \\
\hline $\begin{array}{l}\text { Nijmegen score Vs } \\
\text { NAPSI score }\end{array}$ & $\begin{array}{l}8.47 \pm 7.99 \mathrm{Vs} 11.93 \\
\pm 11.77\end{array}$ & $\begin{array}{l}\mathrm{r}=0.92 \mathrm{p}=0.001 \\
\text { significant }\end{array}$ & $\begin{array}{l}\text { There is a significant, positive, Strong } \\
\text { correlation between Nijmegen score and } \\
\text { NAPSI score }\end{array}$ \\
\hline $\begin{array}{l}\text { Nijmegen score Vs } \\
\text { PASI score }\end{array}$ & $\begin{array}{l}8.47 \pm 7.99 \mathrm{Vs} 7.81 \pm \\
7.62\end{array}$ & $\begin{array}{l}\mathrm{r}=0.29 \mathrm{P}=0.13 \\
\text { not significant }\end{array}$ & $\begin{array}{l}\text { There is a not significant, positive }, \text { Fair } \\
\text { correlation between Nijmegen score and } \\
\text { PASI score }\end{array}$ \\
\hline $\begin{array}{l}\text { NAPSI score Vs PASI } \\
\text { score }\end{array}$ & $\begin{array}{l}11.93 \pm 11.77 \mathrm{Vs} \\
7.81 \pm 7.62\end{array}$ & $\begin{array}{l}\mathrm{r}=0.25 \mathrm{P}=0.21 \\
\text { not significant }\end{array}$ & $\begin{array}{l}\text { There is a not significant, positive }, \text { Fair } \\
\text { correlation between NAPSI score and } \\
\text { PASI score }\end{array}$ \\
\hline
\end{tabular}

Not Sigificant $P>0.05$ AT * significant at $P \leq 0.05 * *$ highly significant at $P \leq 0.01 * * *$ very high significant at $P \leq 0.001$

Table2. Type of Psoriasis Comparison of Nijmegen, Napsi \& Pasi Score

\begin{tabular}{|c|c|c|c|c|c|}
\hline & & $\mathrm{N}$ & Mean & Std. Deviation & $\begin{array}{l}\text { Onaway } \\
\text { ANOVA } \\
\text { F-test }\end{array}$ \\
\hline \multirow[t]{6}{*}{ N-NAIL SCORE } & Nail ps & 1 & 39.00 & 0.00 & \multirow{5}{*}{$\begin{array}{l}F=8.34 \\
P=0.001 \\
\text { significant }\end{array}$} \\
\hline & Plantar ps & 2 & 3.00 & 0.00 & \\
\hline & PPPs & 2 & 4.00 & 2.82 & \\
\hline & Ps.vulgaris & 20 & 8.50 & 6.32 & \\
\hline & Scalp ps & 5 & 6.20 & 2.38 & \\
\hline & Total & 30 & 8.47 & 7.98 & \\
\hline \multirow[t]{6}{*}{ NAPSI SCORE } & Nail ps & 1 & 56.00 & 0.00 & \multirow{5}{*}{$\begin{array}{l}F=7.59 \\
P=0.001 \\
\text { significant }\end{array}$} \\
\hline & Plantar ps & 2 & 4.50 & 2.12 & \\
\hline & PPPs & 2 & 5.00 & 1.41 & \\
\hline & Ps.vulgaris & 20 & 12.00 & 9.35 & \\
\hline & Scalp ps & 5 & 8.60 & 5.98 & \\
\hline & Total & 30 & 11.93 & 11.771 & \multirow{6}{*}{$\begin{array}{l}F=2.78 P=0.05 \\
\text { significant }\end{array}$} \\
\hline \multirow[t]{6}{*}{ PASI SCORE } & Nail ps & 1 & 0.00 & 0.00 & \\
\hline & Plantar ps & 2 & 3.20 & 0.00 & \\
\hline & PPPs & 2 & 4.20 & 0.84 & \\
\hline & Ps.vulgaris & 20 & 10.69 & 7.83 & \\
\hline & Scalp ps & 5 & 1.12 & 0.50 & \\
\hline & Total & 30 & 7.81 & 7.6299 & \\
\hline
\end{tabular}

\section{DisCUSSION}

In the past years attention towards nail psoriasis and the treatment of nail psoriasis is increasing and specific nail psoriasis severity scores are needed. In 2003, Rich et al developed the nail psoriasis severity index (NAPSI), a simple objective tool for the measurement of nail psoriasis severity. It is used to evaluate the severity of nail bed and nail matrix psoriasis by area of involvement in the nail unit. Several other nail psoriasis scoring systems (modified NAPSI, nail area severity, target NAPSI, psoriasis nail severity score and Baran scoring) have also been developed. Each of these tools scores the presence or absence of nail psoriasis manifestations, but they differ in the type of scoring of features included and all have their advantages and disadvantages. Recently, Nijmegan nail psoriasis activity tool (N-NAIL) was developed which reflects better clinical severity than all other nail psoriasis scoring systems. In the N-NAIL, red lunula, oil spot/salmon patch and splinter hemorrhages are not included. Sum of the total score of all involved nails is the total N-NAIL score for that patient at that time. They are scored by percentage of involved area (PASI score) to give an impression of the severity.

Because no gold standard for nail psoriasis severity scoring exists, we did a compare study to find out the correlation between the NAPSI score and N-NAIL score with the severity of the disease (using PASI score). On comparison, we found that males were affected when compared to females, the common age group affected ranged between 21-30 years followed by 41-50 years. According to previous studies, Pitting is the most common abnormality seen in psoriasis in both adults and children. ${ }^{[8][9]}$ Grover et al, reported onycholysis as the most prevalent nail change (76.0\%) of patients. ${ }^{[10]}$ In our 
study, onycholysis $(53.3 \%)$ was the most common abnormality followed by pitting (40\%), subungual hyperkeratosis $(33.3 \%)$, beau's lines $(20 \%)$, crumbling $(6.7 \%)$ and leukonychia $(3.3 \%)$. There was positive correlation between N-NAIL score and NAPSI score (coefficient score of 0.92) as there are few nail changes common in both the scoring system. There was no correlation between NAPSI score, N-NAIL score with the PASI score. On comparison, Nijmegan nail score has few advantages over NAPSI score as it takes only few minutes to calculate and it includes only five nail changes (onycholysis, beau's lines, crumbling, pitting and subungual hyperkeratosis).

\section{Conclusion}

In our study on comparison between the NAPSI score and N-NAIL score, we found that there was no correlation between both the scoring systems with the severity of the disease. Nail psoriasis seems to be an overlooked feature of the disease and hence an adequate nail psoriasis scoring system is necessary to prevent nail psoriasis.

The Nijmegen-Nail psoriasis Activity Index Tool. ${ }^{[1]]}$

\begin{tabular}{|l|l|}
\hline Feature & Manner of scoring \\
\hline Onycholysis/oil-drop discoloration & $0=$ absent \\
& $1=0-25 \%$ \\
& $2=25-50 \%$ \\
\hline Pitting & $3=>50 \%$ \\
& $0=$ absent \\
& $1=$ mild \\
& $2=$ moderate \\
\hline Crumbling & $3=$ severe \\
& $0=$ absent \\
& $1=$ mild \\
& $2=$ moderate \\
\hline Beau's lines & $3=$ severe \\
& $0=$ absent \\
& $1=1$ Beau Line \\
& $2=2$ Beau Lines \\
Subungual hyperkeratosis & $3=\geq 3$ Beau Lines \\
& $0=$ absent \\
& $1=1 \mathrm{~mm}$ \\
& $2=2 \mathrm{~mm}$ \\
& $3=\geq 3 \mathrm{~mm}$ \\
\hline
\end{tabular}

\section{REFERENCES}

[1] Zaias N. Psoriasis of the nail. A clinical-pathologic study. Arch Dermatol 1969; 99: 567-79

[2] Salomon J, Szepietowski JC, Proniewicz A. Psoriatic nails: a prospecti ve clinical study. J Cutan Med Surg 2003; 7:317-21.

[3] Langley RG, Dauden E. Treatment and management of psoriasis with nail involvement: a focus on biologic therapy. Dermatology 2010; 221:29-42.

[4] Parlo-Castello V, Pardo OA, editors. Springfield: Thomas; 1960. Disease of the nails.

[5] Samman PD, editor. 3rd ed. London: Heinemann; 1978. The nails in Disease.

[6] Wilson FC, Icen M, Crowson CS, McEvoy MT, Gabriel SE, Kremers HM. Incidence and clinical predictors of psoriatic arthritis in patients with psoriasis: a population-based study. Arthritis Rheum 2009; 61:233-9.

[7] Gladman DD, Antoni C, Mease P, Clegg DO, Nash P. Psoriatic arthritis: epidemiology, clinical features, course, and outcome. Ann Rheum Dis 2005; 64 14-7.

[8] Kaur I, Saraswat A, Kumar B. Nail changes in psoriasis: a study of 167 patients. Int J Dermatol. 2001; 40:601-3

[9] Kumar B, Jain R, Sandhu K, et al. Epidemiology of childhood psoriasis: a study of 419 patients from northern India. Int J Dermatol. 2004; 43:654-8

[10] Grover C, Reddy BS, Uma Chaturvedi K. Diagnosis of nail psoriasis: importance of biopsy and histopathology. Br J Dermatol 2005; 153:1153-8.

[11] Klaassen KM, van de Kerkhof PC, Bastiaens MT, Plusjé LG, Baran RL, Pasch MC. Scoring nail psoriasis. J Am Acad Dermatol. 2014; 70(6): 1061-6. 